\title{
ANALISIS KEPUASAN KERJA KARYAWAN DI PREMIER BASKO HOTEL BY LARIZ PADANG
}

\author{
Evan Mardua Putra ${ }^{1}$, Lise Asnur ${ }^{2}$ \\ ${ }^{1,2}$ Program Studi D4 Manajemen Perhotelan, Jurusan Pariwisata \\ FPP Universitas Negeri Padang \\ e-mail: evanmardua597@yahoo.com
}

\begin{abstract}
Abstrak
Penelitianuini ditujukan untukcguna melihat kepuasan kerja karyawan di Premier Basko Hotel by Lariz Padang. Jenis penelitian ini adalah jenis penelitian kuantitatif dengan metode survei. Populasi dalam penelitianmini adalah seluruh karyawan premier basko hotel by lariz padang. Sampel yang digunakan adalah sampel jenuh yaitu teknik penentuan sampel apabila semuacanggota populasi digunakan sebagai sampel teknikmpengumpulan data yang digunakan adalah kuisioner yang tersusun atau angket dan dokumentasi. Hasilddari penelitian ini adalah (1)indikator gaji menunjukkan interprestasi penilaian responden $49 \%$ menyatakan kategori setuju dan $40 \%$ menyatakan kategorivcukup, (2)indikator pekerjaan itu sendiri menunjukkan interprestasi peniliaian responden $56 \%$ menyatakan kategori setuju dan $30 \%$ menyatakan kategori cukup, (3)indikator promosi jabatan menunjukkan interprestasi penilaian responden $36 \%$ menyatakan kategori cukup dan $26 \%$ menyatakan kategori tidak setuju, (4)indikatorjsupervisi menunjukkan interprestasi peniliaian responden $57 \%$ menyatakankkategori setuju dan $41 \%$ menyatakan kategori cukup.
\end{abstract}

Kata kunci : Kepuasan Kerja

\begin{abstract}
This research is intended to look at employee job satisfaction at Premier Basko Hotel by Lariz Padang. Thisutype of researchuis a type ofoquantitative research with survey methods. The population in this study were all premier employees of the hotel Basko by lariz padang. The sample used is a saturated sample that isuthe techniqueiof determining the sample if all members of the population are used as samples of data collectiongtechniquesuused are arranged questionnaires or questionnairesuand documentation. Thegresultsuof thishstudy are (1) salary indicators show that respondents 'assessment interpretation $49 \%$ states that the category agrees and $40 \%$ states that the category is sufficient, (2) the work indicator itself shows the evaluation of respondents' evaluation $56 \%$ states the category agrees and $30 \%$ states the category is sufficient, ( 3 ) position promotion indicators show the interpretation of respondents 'assessment $36 \%$ stated that the category was sufficient and $26 \%$ stated the category did not agree, (4) the indicator of supervision showed interpretation of respondents' assessment $57 \%$ stated the category agreed and $41 \%$ stated the category was sufficient.
\end{abstract}

Keywords : Job Satisfaction 


\section{PENDAHULUAN}

Pada saat sekarang ini
perkembangan industry mengalami perkembangan yang sangat pesat hal tersebut dapat dilihat dari jumlah hotel yang bertambah dari tahun 2012-2015 di kota padang. Pada tahun 2012 hotel berjumlah 65, ditahun 2013 menjadi 70, kemudian di tahun 2014 berjumlah 72 dan pada tahun 2015 meningkat menjadi 102 hotel. (sumber: Badan Pusat Statistik, 2016). Perkembangan dunia pariwisata dewasa ini cukup baik, Era globalisasi ini menuntut semua pihak untuk bersaing memperebutkan kedudukan sebagai penentu sektor pariwisata, dalam hal ini dituntut mengembangkan segala macam aspek. Pariwisata merupakan salah satu segi aspek yang harus dikembangkan, karena mempunyai nilai integritas tinggi dalam menentukan kemajuan zaman. Industri pariwisata sangat erat kaitannya dengan dunia perhotelan karena hotel bergerak dalam bidang pelayanan jasa beserta akomodasinya untuk mendukung lancarnya pariwisata di Indonesia (Agus Sulastiyono, 2016). Menurut Susepti (2017) Pariwisata merupakan salah satu industri terbesar dan tercepat perkembangannya di dunia.Sektor ini memberikan kontribusi yang besar untuk perkembangan ekonomi, pengurangan kemiskinan, penyerapan tenaga kerja dan berbagai dampak positif lainnya (ekonomi, sosial, politik, dan budaya). Menurut I Gede Pitana (2009) Pariwisata mempunyai arti rangkaian kegiatan yang berhubungan dengan perjalanan untuk rekreasi, pelancong, dan tourism. Pariwisata adalah tourism yang merupakan kegiatan perjalanan seseorang individu dari tempat tinggal asalnya ke suatu tempat di kota lain ataupun negara lain dalam waktu tertentu dengan tujuan bersenangsenang.

Menurut Arianto (2018) Hotel merupakan salah satu usaha komersial dalam memberikan pelayanan akomodasi, fasilitas, makanan, minuman, transportasi, dan jasa lainya. Hal itu mencakup dari cara mengelola hotel secara profesional, supaya hotel bisa mempertahankan mutu pelayananya, maka harus mengetahui kebutuhan dan keinginan tamu. Industri perhotelan adalah industri jasa yang memadukan antar produk dan layanan, desain bangunan, interior dan eksterior kamar hotel serta restoran, suasana yang tercipta didalam kamar hotel, restoran serta makanan dan minuman yang dijual beserta keseluruhan fasilitas yang ada merupakan contoh produk yang dijual, sedangkan layanan yang di jual adalah keramah - tamahan dan keterampilan
Staff / Karyawan hotel dalam melayani pelangganya. Menurut Ivanovic (2009) Hotel merupakan sarana persinggahan sementara bagi wisatawan termasuk diantaranya memberikan pelayanan kamar serta pelayanan makanan dan minuman, maka hal yang paling penting dari suatu produk hotel yaitu faktor manusia berupa jasa pelayanannya. Menurut Sulastiyono (2011:5) menyebutkan hotel adalah suatu perusahaan yang dikelola oleh pemiliknya dengan menyediakan pelayanan makanan, minuman, dan fasilitas kamar untuk tidur kepada orang-orang yang melakukan perjalanan dan mampu membayar dengan jumlah yang wajar sesuai dengan pelayanan yang diterima tanpa adanya perjanjian khusus. Hotel adalah suatu industri atau usaha jasa yang dikelola secara komersial (Hermawan dkk., 2018).

$$
\text { Menurut Handoko (2011: 3) }
$$

manajemen sumber daya manusia adalah penarikan seleksi, pengembangan, pemeliharaan, dan penggunaan sumber daya manusia untuk mencapai baik tujuan-tujuan individu maupun organisasi. Secanggih apapun teknologi tanpa adanya sumber daya manusia yang mampu menanganinya, maka teknologi tersebut tidak ada arti apapun. Hal ini membuktikan bahwa pencapaian tujuan industry hotel sangat tergantung kepada karyawan yang menggerakkanya. Setiap karyawan secara individual mempunyai kepuasan kerja yang berbeda-beda.

Menurut Robbins (2015: 170) menyebutkan bahwa kepuasan kerja adalah suatu sikap umum terhadap pekerjaan seseorang sebagai perbedaan antara banyaknya ganjaran yang diterima pekerja dengan banyaknya ganjaran yang diyakini seharusnya diterima . Menurut Luthan dalam Umar (2013: 38) indikator kepuasan kerja dibagi atas 5 dimensi yaitu: pekerjaan itu sendiri, promosi jabatan, supervisi, rekan kerja, dan gaji.

1. Gaji

Gaji adalah proses atau cara yang berupa uang dalam membalas jasa atas hasil kerjanya untuk memajukan sebuah perusahaan yang dibayarkan secara periodik.

2. Pekerjaan itu sendiri

Pekerjaan itu sendir adalah suatu posisi/jabatan yang mencakup tugas-tugas poko serta harus bertanggung jawab atas pekerjaan yang akan dilaksanakan sehingga karyawan mampu untuk menguasai pekerjaannya itu sendiri. 
3. Promosi Jabatan

Promosi jabatan adalah perubahan posisi/jabatan ke tingkat yang lebih tinggi dengan tanggung jawab yang lebih besar dan juga sebagai penghargaan atas hasil kerjanya dalam mencapai harapan perusahaan.

4. Supervisi

Supervisi adalah atasan yang berhubungan langsung dengan bahawannya demu kelancaran pekerjaan opersional dan supervisi juga harus bersikap adil kepada bawahannya agar suasana dalam lingkup kerja tersebut bisa terasa nyaman.

5. Rekan Kerja

Rekan kerja adalah pegawai yang berada di dalam suatu perusahaan yang saling bersahabat dan bekertegantungan antara satu dengan yang lainnya untuk menciptakan suasana yang harmonis agar tercapainya suatu tujuan yang akan dituju secara bersama-sama.

Tabel 1. Jumlah Karyawan di Premier Basko Hotel by Lariz Padang

\begin{tabular}{|c|c|c|}
\hline No & Department & Jumlah Karyawan \\
\hline 1 & Food \& Beverage Service & 12 orang \\
\hline 2 & Food \& Beverage Product & 14 orang \\
\hline 3 & Front Office & 10 orang \\
\hline 4 & Housekeeping & 16 orang \\
\hline 5 & Marketing & 4 orang \\
\hline 6 & HRD & 2 orang \\
\hline 7 & Accounting & 4 orang \\
\hline \multirow[t]{2}{*}{8} & Engineering & 8 orang \\
\hline & TOTAL & 70 orang \\
\hline
\end{tabular}

Berdasarkan observasi awal yang penulis lakukan yang berkaitan dengan kepuasan kerja dengan metode wawancara pada tanggal 09 - 20 Mei 2019, seperti komentar (1) 43 orang dari 70 orang atau $61,4 \%$ karyawan mengeluhkan gaji yang mereka terima masih sering terlambat, terkadang dalam satu bulan gaji yang diterima hanya dibayarkan sebagian dan sebagian lagi diterima beberapa minggu kemudian dari hari gajian. (2) 38 orang dari 70 orang atau $54,2 \%$ karyawan mengatakan bahwa di Premier Basko susah untuk berkarir dikarenakan pelatihan karyawan yang masih kurang contohnya pada karyawan Food and Beverage Service dan karyawan administrasi sales marketing yang sudah lama bekerja tapi tidak mendapatkan kesempatan untuk berkarir. Masalah lainnya adalah (3) Karyawan tidak puas karena kurangnya motivasi dari pimpinan per departemen, seperti komentar 35 orang dari 70 orang atau $50 \%$ karyawan mengeluhkan atasan kurang memotivasi kerja bawahan sehingga pada saat karyawan mulai kehilangan semangat dalam bekerja atasan tidak mempedulikan sehingga tidak adanya tercipta kepuasan kerja. (4) Kurangnya pelatihan dari atasan dan hanya kepada orang tertentu yang terpillih untuk mendapatkan pelatihan, seperti komentar 36 orang dari 70 orang atau $51,4 \%$ karyawan mengeluhkan mereka tidak puas terhadap pekerjaannya dikarenakan kurangnya pelatihan dan pengarahan langsung dari atasan, terkadang atasan juga tidak kroscek ulang hasil kerja karyawan sehingga tidak tercipatnya kepuasan kerja terhadap pekerjaan itu sendiri.

Kepuasan kerja karyawan ini menjadi penting karena akan berdampak langsung pada hasil kinerja karyawan itu sendiri. Terciptanya kepuasaan karyawan dalam bekerja akan menjadi sebuah keuntungan bagi perusahaan. Bagaimana tidak, jika suatu perusahaan sudah mendapat hasil kerja yang bagus dari karyawan, maka perusahaan secara otomatis mendapat nilai tambah sehingga para tamu yang berkunjung juga menjadi puas dan melakukan proses pembelian ulang. Berdasarkan fenomena di atas dengan beberapa faktor yang mempengaruhi kepuasan kerja karyawan di Hotel Premier Basko Padang, maka penulis melakukan penelitian dengan judul "Analisis Kepuasan Kerja Karyawan Di Hotel Premier Basko by Lariz Padang". Karena Kepuasan karyawan ditentukan dari sikap atasan yang bertanggung jawab dan tegas dalam menjalankan tugasnya serta adanya kenaikan jenjang karir seorang karyawan. Oleh karena itu penelitian ini diharapkan dapat memberikan informasi kepada pihak hotel dalam mengetahui tingkat kepuasan kerja karyawan sehingga dapat meningkatkan mutu dari hotel tersebut. 


\section{METODE}

Jenis penelitian yang akan digunakan pada penelitian ini adalah jenis penelitian kuantitatif dengan metodesurvei. Populasi dalam penitian ini adalah seluruh karyawan di Premier Basko Hotel by Lariz Padang. Sampel yang digunakan adalah sampel jenuh, sampel jenuh dalah teknik penentuan sampel apabila semua anggota populasi digunakan sebagai sampel.

Jenis data yang digunakan dalam penelitian ini adalah datakprimer dan data sekunder. Data primer yang terkait ialah data yang dikumpulkan oleh peneliti terhadap sasaran dengan cara menyebar angket. Sedangkan data sekunder diperoleh secara tidak langusng dari objek penelitian dengan memanfaatkan data ada dari HRD Hotel Padang. yang telah Basko Teknik pengumpulan data yang digunakan adalah kuisioner atau angket yang tersusun dan dokumentasi. Instrument penelitian yang digunakan adalah kuisioner yang disusun dengan bentuk skala likert yang dijelaskan oleh sugiyono (2015: 9), "Skala likert merupakan salah satu bentuk skala pengukuran yang digunakan untuk fenomena sikap, pendapat, dan persepsi seseorang atau kelompok tentang kejadian sosial. kemudian teknik alanisis data yang digunakan dalam penelitian ini adalah editing, tabulating, analiting dan interprestasi, dan concluding.

\section{HASIL DAN PEMBAHASAN}

Data penelitian ini diperoleh dari hasil pengisian instrument berupa pernyataan kepada karyawan yang bekerja di Premier Basko Hotel by Lariz Padang yang terdiri dari 30 item. Dapat dilihat pada tabel 2 berikut:

Tabel 2. Data Hasil Perhitungan Statistik kepuasan kerja Di Premier Basko Hotel by Lariz Padang

\begin{tabular}{lcc}
\hline \multirow{1}{*}{$\mathbf{N}$} & Valid & $\mathbf{7 0}$ \\
\cline { 2 - 3 } & Missing & $\mathbf{0}$ \\
\hline Mean & & 102.34 \\
Median & 103 \\
Mode & 100 \\
Std. Deviation & 8.60 \\
Range & 41 \\
Minimum & 80 \\
Maximum & 121 \\
Sum & 7164 \\
\hline
\end{tabular}

Berdasarkan Tabel 2 diatas dapat terlihat data mengenai kepuasan kerja karyawan yang diambil melalui angket berjumlah 30 butir pernyataan yang diberikan kepada 70 orang responden diperoleh nilai mean 102.34, median 103, mode 100 , standar deviasi 8.60 , nilai minimum 80 , nilai maksimum 121 , dan total nilai sebesar
7164. Deskripsi menurut masingmasing indikator adalah sebagai berikut:

a) Gaji

Deskripsi penilaian responden tentang gaji di premier basko hotel by lariz padang dapat dilihat di tabel 3 berikut:

Tabel 3. Deskripsi Penilaian Responden Tentang Gaji di Premier Basko Hotel by Lariz Padang

\begin{tabular}{lccc}
\hline \multicolumn{1}{c}{ Kategori } & Gatas Interval & Frekuensi & Persentase (\%) \\
\hline Sangat Setuju & $4.21-5.0$ & 6 & 9 \\
Setuju & $3.41-4.20$ & 34 & 49 \\
Cukup & $2.61-3.40$ & 28 & 40 \\
Tidak Setuju & $1.81-2.60$ & 2 & 3 \\
Sangat Tidak Setuju & $1-1.8$ & 0 & 0 \\
\hline \multicolumn{1}{c}{ Total } & & $\mathbf{7 0}$ & $\mathbf{1 0 0}$ \\
\hline
\end{tabular}


Berdasarkan Tabel 3 di atas tentang penilaian responden tentang gaji, $9 \%$ responden termasuk kategori sangat setuju, 49\% responden termasuk kategori setuju, 40\% responden termasuk kategori cukup. Dan ada 3\% responden termasuk kategori tidak setuju. Penilaian responden terhadap gaji yang dilakukan oleh pihak Hotel Premier Basko
Padang termasuk dalam kategori setuju, dengan perolehan skor $49 \%$.

b) Pekerjaan itu sendiri

Deskripsi penilaian responden di premier basko hotel by lariz padang dapat dilihat di tabel 4 berikut:

Tabel 4. Deskripsi Penilaian Responden Tentang Pekerjaan Itu Sendiri

\begin{tabular}{lccc}
\hline & \multicolumn{2}{c}{ Pekerjaan itu Sendiri } & \\
\hline \multicolumn{1}{c}{ Kategori } & Batas Interval & Frekuensi & Persentase (\%) \\
\hline Sangat Setuju & $4.21-5.0$ & 6 & 9 \\
Setuju & $3.41-4.20$ & 39 & 56 \\
Cukup & $2.61-3.40$ & 21 & 30 \\
Tidak Setuju & $1.81-2.60$ & 4 & 6 \\
Sangat Tidak Setuju & $1-1.8$ & 0 & 0 \\
\hline \multicolumn{1}{c}{ Total } & & $\mathbf{7 0}$ & $\mathbf{1 0 0}$ \\
\hline
\end{tabular}

Berdasarkan Tabel 4 di atas tentang penilaian responden tentang pekerjaan itu sendiri, 9\% responden termasuk kategori sangat setuju, $56 \%$ responden termasuk kategori setuju, 30\% responden termasuk kategori cukup. Dan ada 6\% responden termasuk kategori tidak setuju. Penilaian responden terhadap pekerjaan itu sendiri yang dilakukan oleh pihak Hotel Premier Basko Padang termasuk dalam kategori setuju, dengan perolehan skor $56 \%$.

c) Promosi Jabatan

Deskripsi penilaian responden di premier basko hotel by lariz padang dapat dilihat pada tabel 5 berikut ini:

Tabel 5. Deskripsi Penilaian Responden Tentang Promosi

\begin{tabular}{lccc}
\hline & \multicolumn{2}{c}{ Promosi Jabatan } & \\
\hline \multicolumn{1}{c}{ Kategori } & Batas Interval & Frekuensi & Persentase (\%) \\
\hline Sangat Setuju & $4.21-5.0$ & 5 & 7 \\
Setuju & $3.41-4.20$ & 21 & 30 \\
Cukup & $2.61-3.40$ & 25 & 36 \\
Tidak Setuju & $1.81-2.60$ & 18 & 26 \\
Sangat Tidak Setuju & $1-1.8$ & 1 & 1 \\
\hline \multicolumn{1}{c}{ Total } & & $\mathbf{7 0}$ & $\mathbf{1 0 0}$ \\
\hline
\end{tabular}

Berdasarkan Tabel 5 di atas tentang penilaian responden tentang promosi jabatan, $7 \%$ responden termasuk kategori sangat setuju, $30 \%$ responden termasuk kategori setuju, $36 \%$ responden termasuk kategori cukup. 26\% responden termasuk kategori tidak setuju, dan $1 \%$ responden termasuk kategori sangat tidak setuju. Penilaian responden terhadap promosi jabatan yang dilakukan oleh pihak Hotel Premier Basko Padang termasuk dalam kategori cukup, dengan perolehan skor $36 \%$.

d) Supervisi

Deksripsi penilaian responden di premier basko hotel by lariz padang dapat dilihat pada table 6 berikut ini: 
Tabel 6. Deskripsi Penilaian Responden Tentang Supervisi

\begin{tabular}{lccc}
\hline \multicolumn{1}{c}{ Supervisi } & \\
\hline \multicolumn{1}{c}{ Kategori } & Batas Interval & Frekuensi & Persentase (\%) \\
\hline Sangat Setuju & $4.21-5.0$ & 1 & 1 \\
Setuju & $3.41-4.20$ & 40 & 57 \\
Cukup & $2.61-3.40$ & 29 & 41 \\
Tidak Setuju & $1.81-2.60$ & 0 & 0 \\
Sangat Tidak Setuju & $1-1.8$ & 0 & 0 \\
\hline \multicolumn{1}{c}{ Total } & & $\mathbf{7 0}$ & $\mathbf{1 0 0}$ \\
\hline
\end{tabular}

Berdasarkan Tabel 6 di atas tentang penilaian responden tentang supervisi, $1 \%$ responden termasuk kategori sangat setuju, $57 \%$ responden termasuk kategori setuju, Dan $41 \%$ responden termasuk kategori cukup. Penilaian responden terhadap supervisi yang dilakukan oleh pihak Hotel Premier Basko Padang termasuk dalam kategori setuju, dengan perolehan skor $57 \%$.

Penelitian ini telah menemukan gambaran kepuasan kerja karyawan di Hotel Premier Basko Padang. Berdasarkan analisa data di atas, interpretasi kepuasan kerja dijabarkan perindikator. Namun secara umum dapat dinyatakan bahwa, kepuasan kerja karyawan di Hotel Premier Basko Padang menunjukkan interpretasi persentase penilaian secara dominan tergolong setuju sebesar $51 \%$ dari 70 orang responden.

Selanjutnya hal ini bisa kita lihat Hotel Premier Basko Padang belum memberikan kepuasan kerja yang maksimal sesuai dengan harapan karyawan yang bekerja. Walaupun sudah dikategorikan setuju, pihak Hotel harus meningkatkan kepuasam kerja agar penilaian karyawan yang bekerja dikategorikan sangat setuju. Sesuai dengan teori menurut Menurut Mangkunegara (2013: 10), "Kepuasan kerja adalah suatu perasaan yang menyokong atau tidak menyokong diri karyawan yang berhubungan dengan pekerjaannya maupun dengan kondisi dirinya". Dari teori yang ada jelas terlihat kepuasan kerja yang diberikan Hotel Premier Basko Padang belum secara maksimal memenuhi kebutuhan dan keinginan karyawan sesuai dengan ekspektasi karyawan yang ditinjau dari 4 indikator kepuasan kerja. Dapat kita lihat kepuasan kerja ditinjau dari 4 indikator kepuasan kerja sebagai berikut:

\section{Gaji}

Kepuasan kerja karyawan di Hotel Premier Basko Padang ditinjau dari indikator gaji dominan dikategorikan setuju dengan interpretasi persentase penilaian $49 \%$ dari 70 responden. Dalam hal ini bisa kita lihat Hotel Premier Basko belum memberikan kepuasan yang maksimal sesuai dengan harapan karyawan yang bekerja ditinjau dari indikator gaji. Dapat dilihat pernyataan angket yang dinilai oleh karyawan yang perlu diperbaiki yaitu gaji yang diterima tidak tepat waktu yang tidak sesuai dengan tanggal penerimaan gaji perbulan, gaji yang diperoleh tidak sesuai dengan jabatan, kenaikan gaji tidak sesuai dengan penimgkatan prestasi kerja.

Sesuai dengan teori menurut Mulyadi dalam Aradea (2018: 10) menjelaskan bahwa, "Gaji adalah pembayaran atau penyerahan jasa yang dilakukan oleh karyawan yang mempunyai jenjang jabatan manajer, sedangkan upah umumnya merupakan pembayaran atas penyerahan jasa yang dilakukan oleh karyawan pelaksana (buruh). Umumnya gaji dibayarkan secara tetap perbulan, sedangkan upah dibayarkan berdasarkan hari kerja, jam kerja, atau jumlah satuan produk yang dihasilkan".

Dari teori yang ada jelas terlihat kepuasan kerja yang diberikan Hotel Premier Basko ditinjau dari indikator gaji sudah memenuhi kebutuhan dan keinginan karyawan tetapi belum mencapai hasil maksimal sesuai dengan ekspetasi karyawan yang bekerja di Hotel Premier Basko Padang.

\section{Pekerjaan Itu Sendiri}

Kepuasan kerja karyawan di Hotel Premier Basko Padang ditinjau dari indikator pekerjaan itu sendiri dominan dikategorikan setuju dengan interpretasi persentase penilaian $56 \%$ dari 70 orang responden. Dalam hal ini bisa kita lihat Hotel Premier Basko Padang belum memberikan kepuasan yang maksimal sesuai dengan harapan karyawan yang bekerja ditinjau dari indikator pekerjaan itu sendiri. Dapat dilihat pernyataan angket yang dinilai oleh karyawan yang perlu diperbaiki yaitu karyawan yang tidak bertanggung jawab atas pekerjaannya sendiri.

Sesuai dengan teori menurut Pujangkoro dalam Aradea (2018: 12) menjelaskan bahwa, "Pekerjaan merupakan sekumpulan kedudukan (posisi) yang 
memiliki persamaan kewajiban atau tugastugas pokoknya. Dalam kegiatan analisis jabatan, satu pekerjaan dapat diduduki oleh satu orang, atau beberapa orang yang tersebar di berbagai tempat". Dari teori yang ada jelas terlihat kepuasan kerja yang diberikan Hotel Premier Basko ditinjau dari indikator pekerjaan itu sendiri sudah memenuhi kebutuhan dan keinginan karyawan tetapi belum mencapai hasil maksimal sesuai dengan ekspetasi karyawan yang bekerja di Hotel Premier Basko Padang.

\section{Promosi Jabatan}

Kepuasan kerja karyawan di Hotel Premier Basko Padang ditinjau dari indikator promosi jabatan dominan dikategorikan cukup dengan interpretasi persentase penilaian $36 \%$ dari 70 orang responden. Dalam hal ini bisa kita lihat Hotel Premier Basko Padang belum memberikan kepuasan yang maksimal sesuai dengan harapan karyawan yang bekerja ditinjau dari indikator promosi jabatan. Dapat dilihat pernyataan angket yang dinilai oleh karyawan yang perlu diperbaiki yaitu setiap karyawan tidak mendapatkan kesempatan yang sama untuk promosi jabatan, kenaikan jabatan tidak didasarkan atas prestasi kerja setiap karyawan, dan promosi karyawan yang dilakukan tidak transparan.

Sesuai dengan teori menurut Wahyudi dalam Aradea (2018: 14) menjelaskan bahwa "Promosi adalah perubahan posisi/jabatan atau pekerjan dari tingkat yang lebih rendah ke tingkat yang lebih tinggi, biasanya akan diikuti dengan meningkatnya tanggung jawab, hak serta status sosial seseorang". Dari teori yang ada jelas terlihat kepuasan kerja yang diberikan Hotel Premier Basko ditinjau dari indikator promosi jabatan sudah memenuhi kebutuhan dan keinginan karyawan tetapi belum mencapai hasil maksimal sesuai dengan ekspetasi karyawan yang bekerja di Hotel Premier Basko Padang.

\section{Supervisi}

Kepuasan kerja karyawan di Hotel Premier Basko Padang ditinjau dari indikator supervisi dominan dikategorikan setuju dengan interpretasi persentase penilaian $57 \%$ dari 70 orang responden. Dalam hal ini bisa kita lihat Hotel Premier Basko Padang belum memberikan kepuasan yang maksimal sesuai dengan harapan karyawan yang bekerja ditinjau dari indikator supervisi. Dapat dilihat pernyataan angket yang dinilai oleh karyawan yang perlu diperbaiki yaitu supervisor memberikan tugas yang tidak sesuai dengan kemampuan karyawan, jadwal/schedule yang diberikan supervisor memberatkan karyawan, supervisor tidak memberikan beban kerja yang merata kepada semua karyawan.

Sesuai dengan teori Menurut Ahmad dalam Aradea (2018: 16) menjelaskan bahwa "Supervisor adalah manajer yang bertanggung jawab kepada manajer yang lebih tinggi dan tugas utamanya memimpin pekerja pada taraf operasional". Dari teori yang ada jelas terlihat kepuasan kerja yang diberikan Hotel Premier Basko ditinjau dari indikator supervisi sudah memenuhi kebutuhan dan keinginan karyawan tetapi belum mencapai hasil maksimal sesuai dengan ekspetasi karyawan yang bekerja di Hotel Premier Basko Padang.

\section{PENUTUP}

Secara keseluruhan kepuasan kerja karyawan di Hotel Premier Basko Padang $51 \%$ menyatakan kategori setuju, dan $49 \%$ menyatakan kategori cukup. Sedangkan berdasarkan indikator dapat dilihat berikut i ni: 1) Indikator gaji, menunjukkan interprestasi penilaian responden $49 \%$ menyatakan kategori setuju dan $40 \%$ menyatakan kategori cukup; 2) Indikator pekerjaan itu sendiri, menunjukkan interprestasi penilaian responden 56\% menyatakan kategori setuju dan 30\% menyatakan kategori cukup; 3) Indikator promosi jabatan, menunjukkan interprestasi penilaian responden 36\% menyatakan kategori cukup dan 26\% menyatakan kategori tidak setuju; 4) Indikator supervisi, menunjukkan interprestasi penilaian responden $57 \%$ menyatakan kategori setuju dan $41 \%$ menyatakan kategori cukup.

\section{DAFTAR PUSTAKA}

Agus Sulastiyono. 2016. Manajemen Penyelengaraan Hotel. Bandung : Alfabeta

Arianto, Nurmin, Jefri Muhammad. 2018. Pengaruh Fasilitas dan Pelayanan terhadap Kepuasan Pengunjung pada Hotel Dharmawangsa. Jurnal Semarak,Vol. 1,No.1, Hal. 107-115. Tersedia Pada: http://openjournal.unpam.ac.id/index.p $\mathrm{hp} / \mathrm{smk} /$ article/view/1250. 
Handoko. 2011. Manajemen Sumber Personalia \& Sumber daya manusia. Penerbit BPFE Yogyakarta.

Hermawan, H., Brahmanto, E dan Faizal H. 2018. Pengantar Manajemen Hospitality. Pekalongan: Penerbit NEM.

HRD Premier Basko Hotel By Lariz Padang. 2019. Data karyawan Premier Basko Hotel By Lariz Padang.

I Gede Pitana dan I ketut Surya Diarta. 2009. Pengantari IImu Pariwisata.Yogyakarta: Penerbit Andi

Ivanovic. M., at al. 2009. Tourism Development Fresh Perspectives. Pearson Education and Prentice Hall.

Robbins, Stephen P. 2015. Perilaku organisasi.

Edisi keenambelas. Jakarta : PT Indeks Gramedia.

Sugiyono. 2018. Metode Penelitian Kuantitatif, Kualitatif, dan R\&D. Bandung: Alfabeta.

Sulastiyono. 2011. Manajemen Penyelenggaraan Hotel: Manajemen hotel,Bandung. Alfabet.

Susepti, Amalia, Djamhur Hamid, Andriani Kusumawati. 2017. Pengaruh Kualitas Pelayanan Terhadap Kepuasan Dan Loyalitas Tamu Hotel (Studi tentang Persepsi Tamu Hotel Mahkota Plengkung Kabupaten Banyuwangi). Jurnal Administrasi Bisnis (JAB)|Vol. 50 No. 5 Hal. 27-36. Tersedia Pada: administrasibisnis.studentjournal.ub.ac .id 3. 